\title{
A CONTRIBUIÇÃO DA MÚSICA PARA O DESENVOLVIMENTO E APRENDIZAGEM NA EDUCAÇÃO INFANTIL
}

\author{
https://dx.doi.org/10.48097/2674-8673.2022n6p02
}

\author{
Jéssica Azevedo Silva ${ }^{1}$ \\ Rafaela Priscila Lima da Silva ${ }^{2}$ \\ Vanessa Cordeiro Vieira ${ }^{3}$ \\ Silvia R. C. Alves Isaltino ${ }^{4}$
}

\section{RESUMO}

Este artigo tem como finalidade compreender o envolvimento da música no processo de desenvolvimento e aprendizagem na educação infantil pelas alunas do curso de Pedagogia da Faculdade Metropolitana da Grande Recife. O estudo teve como objetivo Compreender o impacto da música no desenvolvimento e aprendizagem na educação infantil. O levantamento e a análise foram realizados por meio de uma pesquisa qualitativa exploratória, com entrevista semiestruturada, aplicada no ano de 2020. A amostra revelou que as entrevistadas destacam a importância de se trabalhar com a música no ambiente escolar e os benefícios que a mesma traz.

Palavras-chave: Música. Desenvolvimento. Aprendizagem. Educação Infantil.

Data de submissão: $16 / 08 / 2021$

Data de aprovação: 19/09/2021

\begin{abstract}
This article aims to understand the involvement of music in the process of development and learning in early childhood education by students of the Pedagogy course at Faculdade Metropolitana da Grande Recife. The study aimed to understand the impact of music on development and learning in early childhood education. The survey and analysis were carried out through an exploratory qualitative research, with semi-structured interviews, applied in 2020. The sample revealed that the interviewees highlight the importance of working with music in the school environment and the benefits it brings.
\end{abstract}

Keywords: Music. Development. Learning. Child education.

\section{INTRODUÇÃO}

O presente trabalho visa estudar a música na educação infantil, buscando

\footnotetext{
${ }^{1}$ Concluinte do curso de Pedagogia da Faculdade Metropolitana da Grande Recife.

E-mail: jessicaazevedosilva90@gmail.com

${ }^{2}$ Concluinte do curso de Pedagogia da Faculdade Metropolitana da Grande Recife.

E-mail: rafa_pri.com@hotmail.com

${ }^{3}$ Concluinte do curso de Pedagogia da Faculdade Metropolitana da Grande Recife.

E-mail: vanessacv1997@hotmail.com

${ }^{4}$ Docente orientadora do curso de Pedagogia da Faculdade Metropolitana da Grande Recife.

E-mail: silvinharca@hotmail.com
} 
compreender qual a sua relação com o processo de desenvolvimento e aprendizagem das crianças nessa fase educativa e o impacto que ela provoca dentro do contexto escolar.

Conforme se sabe, a música é uma linguagem muito importante para o desenvolvimento humano, pois é um meio de expressar sentimentos, ideias, emoções, pensamentos, etc. Intimamente relacionada com a cultura local, a música faz parte de momentos e situações sociais, podendo, inclusive, estar presente antes mesmo do nascimento da criança, quando esse contato acontece ainda no ventre da mãe. A musicalidade também aparece em rituais como casamentos, nascimentos, mortes, recuperação de doenças e fertilidade. Assim, conforme aponta Bréscia (2003), a música faz parte de diversas culturas, em todos os aspectos da história em que o ser humano está inserido, desde as primeiras civilizações.

É nesse contexto que se ressalta a relevância da música na educação infantil, abordando o desenvolvimento em uma perspectiva lúdica, facilitando, assim, a aprendizagem da criança, através de suas expressões e emoções. O ensino de leitura e escrita através da música funciona como um processo mediador que tem como finalidade desenvolver e potencializar a construção de conhecimentos e habilidades, contribuindo na formação da criança.

Deste modo, a música está muito ligada ao lúdico e ao brincar. Em todos os povos as crianças brincam com a música. Jogos e brinquedos musicais, como as rodas cantadas, são encontrados nos lugares onde houver crianças. (UNESCO, 2005).

Somada ao fato acima exposto, a motivação da pesquisa surge devido à experiência profissional e pessoal das presentes pesquisadoras, pois se identificam bastante com o tema e o reconhecem como recorrente nos dias atuais, podendo trazer benefícios tanto na relação do professor com os alunos como na relação dos alunos entre si. Dessa forma, pretende-se contribuir com as discussões e os estudos da área e ampliar a compreensão sobre o impacto da musicalidade no contexto educacional.

\section{FUNDAMENTAÇÃO TEÓRICA}

Em relação à educação infantil, a música tem um papel indispensável na vida da criança, pois contribui para a formação cognitiva, física, mental e social do indivíduo, incentivando também os cuidados com o corpo e a alimentação. Para isso, Moreno (2007) destaca que “o trabalho pedagógico na educação infantil deve 
respeitar a criança quanto aos seus direitos e especificidades, isto é, sua essência lúdica, sua constante curiosidade, seu desenvolvimento".

\section{A música e o desenvolvimento humano}

Observando a música na história da humanidade é possível perceber que ela é fundamental na vida dos seres humanos, estando presente em diferentes momentos, desde a antiguidade, fazendo parte das mais variadas culturas e regiões. Nesse sentido, Góes (2009) ressalta que:

A presença da música na vida dos seres humanos é incontestável. Ela tem acompanhado a história da humanidade, ao longo dos tempos, exercendo as mais diferentes funções. Está presente em todas as regiões do globo, em todas as culturas, em todas as 12 épocas, ou seja, a música é uma linguagem universal, que ultrapassa as barreiras do tempo e do espaço. (GÓES, 2009, p. 2).

Além disso, a música pode contribuir para o desenvolvimento humano, visto que é uma importante forma de comunicação e está presente em diferentes etapas da vida humana, trazendo benefícios para este processo formativo. (NOGUEIRA, 2003).

Dentro do contexto escolar a música também tem a sua contribuição, funcionando para fortalecer os vínculos aluno-aluno e professor-aluno, além de ter a capacidade de desenvolver a psicomotricidade, as expressões, o equilíbrio, a autoestima, o autoconhecimento, etc.

Segundo o Referencial Curricular Nacional para a Educação Infantil, do Ministério da Educação e do Desporto:

O trabalho com a música deve considerar, portanto, que ela é um meio de expressão e forma de conhecimento acessível aos bebês e crianças, inclusive aquelas que apresentam necessidades especiais. A linguagem musical é excelente meio para o desenvolvimento da expressão do equilíbrio da autoestima e autoconhecimento, além de poderoso meio de interação social. (BRASIL, 1998, p. 49).

Assim, destaca-se que há uma grande variedade de formas para trabalhar a música na sala de aula. Esta deve ser valorizada também nos momentos da brincadeira, pois se compreende que brincando também se aprende. A forma de musicalidade lúdica é uma maneira prazerosa de compreender e aprender gestos, sílabas, sons e pronúncias.

Conforme descrição de Arribas (2006):

O ritmo na música é a maneira de suceder-se e alternarem-se os sons (sílabas, pulsações), e destes, seus acentos fortes e fracos, suas durações curtas ou longas. A melodia, procedente a linguagem, é a linha horizontal da 
música (um som após o outro) A harmonia é a fusão e a simultaneidade dos sons, é a verticalidade da música. (ARRIBAS, 2006, p. 245).

Ao colocar uma música o professor pode incentivar as crianças com gestos, danças ou até mesmo com os próprios sons corporais. Brincadeiras como danças de roda e danças da cadeira possibilitam o desenvolvimento da concentração. Ademais, a música permite o autocontrole do próprio corpo, melhora a postura, percepção auditiva, noção rítmica e espacial, incentivando também o desenvolvimento da linguagem. Nesse sentido, Oliveira (1997) destaca:

\begin{abstract}
A fala para a criança é um ato motor organizado, exige, além de uma adequada percepção auditiva e visual, um conhecimento e controle do corpo, através das posturas e gestos; uma orientação espacial que lhe facilite sua movimentação; uma coordenação adequada para compreensão dos conceitos verbais; uma capacidade de simbolização uma estruturação temporal que permite à criança adquirir o ritmo e as seqüências para uma emissão da fala mais fluida. (OLIVEIRA, 1997, p. 108).
\end{abstract}

Dessa forma, percebe-se que a música é algo indispensável na vida do indivíduo, pois exerce uma grande influência em seus aspectos corporais, linguísticos e sentimentais, contribuindo também para uma aprendizagem prazerosa, lúdica e divertida.

\title{
A importante etapa da educação infantil
}

A educação infantil é uma fase primordial na vida das crianças, pois tem o papel de contribuir com a ação da família e da sociedade no seu desenvolvimento e socialização. É nesta etapa que as crianças constroem laços afetivos e têm os primeiros contatos com outras crianças. Assim diz a legislação de $n^{\circ}$ 9394/96 (Lei de Diretrizes e Bases da Educação Infantil):

A educação Infantil, primeira etapa da educação básica, tem como finalidade o desenvolvimento integral da criança até seis anos de idade, em seus aspectos físico, psicológico, intelectual e social, complementando a ação da família e da comunidade. (BRASIL, 1996).

Para tanto, é importante que se reconheça que a criança precisa ser vista como única nas suas necessidades e características, levando em consideração que cada uma tem o seu próprio tempo e modo para desenvolver-se. Além disso, o ambiente educativo precisa ser adequado, seguro, positivamente estimulante e alegre, para que permita a integração dos cuidados com as crianças. Com a organização do espaço adequado a criança poderá desenvolver o seu imaginário com a leitura do ambiente que a mesma está inserida. O Referencial Curricular Nacional para a Educação Infantil diz que 


\begin{abstract}
A organização do espaço físico das instituições de educação infantil deve levar em consideração todas as dimensões humanas potencializadas nas crianças: o imaginário, o lúdico, o artístico, o afetivo, o cognitivo etc. (BRASIL, 1998, p. 58).
\end{abstract}

Ademais, não se pode esquecer que desde essa etapa inicial as crianças começam a formar suas personalidades, a criar laços afetivos e a se socializar com outros e com o meio em que vivem. Assim, uma educação de qualidade, além de proporcionar a aprendizagem, precisa contemplar os interesses e elementos da vivência das crianças, sem negligenciar a leveza e a diversão que a fase da infância supõe.

É nesta direção que a ludicidade se apresenta como importante elemento da educação infantil, visto que proporciona que o aprendizado e o desenvolvimento sejam estimulados de forma mais agradável e natural, permitindo uma forma mais ativa e significativa dentro do ambiente escolar.

Levando em consideração o papel que a ludicidade ocupa na aprendizagem dentro da educação infantil, se faz necessário refletir sobre esses recursos lúdicos que fazem e podem fazer parte do dia a dia das escolas, de modo a aprimorar o seu uso e potencializar o caráter estimulador e ampliador de conhecimentos que esses recursos possuem. Nesse caso, o foco aqui se volta para a musicalidade, o local que ela ocupa e as contribuições que a mesma pode trazer nesta etapa escolar.

\title{
A música na educação infantil
}

Através do levantamento bibliográfico na área em questão, foi possível perceber que inúmeros estudos apontam a contribuição da música na educação infantil, sendo considerada como facilitadora do desenvolvimento e do aprendizado da criança, quando utilizada enquanto mediadora do processo do ensino e aprendizagem. Segundo Gilioli (2008): “A música na educação infantil auxilia no desenvolvimento psicomotor, contribui no processo de socialização e aproxima a criança da arte".

Assim, a música permite estimular as dimensões cognitiva e psicomotora da criança, oferecendo benefícios para o desenvolvimento de habilidades e capacidades.

Faria (2001) ressalta que:

A música como sempre esteve presente na vida dos seres humanos, ela também sempre está presente na escola para dar vida ao ambiente escolar e favorecer a socialização dos alunos, além de 
despertar neles o senso de criação e recreação. (FARIA, 2001, p. 24).

O referido autor destaca também que o uso da música contribui diretamente no meio social e afetivo do indivíduo, permitindo, assim, a ação direta do criar e recriar. Contudo, é importante ressaltar que para alcançar os objetivos propostos a música deve ser utilizada de maneira planejada, adequada e através de atividades bem desenvolvidas, pois se utilizada sem esses cuidados pode perder o seu potencial estimulador e criativo. De acordo com Godoi (2011), atividades mecânicas esvaziadas de sentidos e visando a mera memorização de músicas pode gerar desinteresse e não trazer contribuição para o aprendizado.

Visto que a criança tende a desenvolver-se de acordo com os estímulos recebidos, a música também ajuda a desenvolver a audição, concentração e efeitos sonoros através de diferentes sons. Chirarelli (2005) acrescenta:

Por isso, é fundamental fazer uso de atividades de musicalização que explorem o universo sonoro, levando as crianças a ouvir com atenção, analisando, comparando os sons e buscando identificar as diferentes fontes sonoras. Isso irá desenvolver sua capacidade auditiva, exercitar a atenção, concentração e a capacidade de análise e seleção de sons. (CHIARELLI, 2005, p. 5).

Ainda que o processo de descoberta e de exploração da música seja uma atividade de extrema importância, se feita de maneira isolada, essa prática tende a consistir em uma visão reduzida do olhar do professor, se considerada as diversas práticas pedagógicas que podem ser realizadas com a música. (NOGUEIRA, 2005).

Por fim, vale ressaltar que a lei de número 11.769 altera a LDB (Lei de Ditretrizes e Bases Nacionais), destacando que a musicalização passou a ser prática obrigatória em todas as instituições de ensino, podendo ser trabalhada de diferentes formas como canção, movimentos corporais com música, músicas utilizadas em brincadeiras, músicas e ritmo através de palmas e batidas, com instrumentos musicais, histórias cantadas, alternância de ritmos e estilos de músicas.

\section{METODOLOGIA}

Tendo em vista alcançar os objetivos propostos, o presente estudo foi desenvolvido através da abordagem qualitativa exploratória. De acordo com Ribeiro (2006):

Pesquisar qualitativamente é, antes de qualquer outra definição, respeitar o ser humano em sua diversidade. É 
entender que há singularidade em cada uma das pessoas envolvidas e que essa singularidade é construída na pluralidade; nas múltiplas etnias, nas pluri-manifestações culturais, corporais, lingüísticas. É gostar de ser gente. (RIBEIRO, 2006, p. 40).

Para isso, foi realizado um estudo de campo através da aplicação de entrevistas semiestruturadas. Marconi e Lakatos (2007) ressaltam que nesse tipo de entrevista o pesquisador tem liberdade para desenvolver a situação na direção que considera adequada, explorando mais amplamente o diálogo, visando assim encontrar as respostas pelas quais se procuram.

Nesse sentido, a pesquisa contou com cinco (05) participantes, sendo: três (03) professores que atuam em ciclos diferentes da educação infantil da rede privada de ensino, uma (01) coordenadora que também é professora de inglês em uma escola privada e uma (01) coordenadora de escola privada que também é vice-dirigente da rede municipal. Todos os entrevistados foram analisados para a coleta de dados da pesquisa.

Devido à pandemia da COVID-19, a coleta de dados precisou acontecer de forma virtual, através dos aplicativos "Zoom" e "Google Meet". Os materiais utilizados foram: celular, notebook, roteiro das entrevistas, caderno e lápis para anotações. Assim, as entrevistas foram conduzidas individualmente nos horários escolhidos pelas participantes.

\section{RESULTADOS}

O presente capítulo foi construído a partir da análise dos dados obtidos por meio da pesquisa de campo. As entrevistas realizadas serão aqui discutidas e relacionadas com teoria das áreas em questão, ampliando assim o campo de conhecimento sobre oreferido tema.

Primeiramente, foi possível constatar a concepção das entrevistadas sobre a importância de trabalhar com a música no cotidiano escolar, percebendo na fala das professoras e coordenadoras o impacto que a musicalidade pode causar no processo de desenvolvimento e aprendizagem das crianças, destacando-se a presença da ludicidade nesse processo, proporcionando intervenção e momentos educativos que sem a música não aconteceriam. É possível perceber isso nos seguintes recortes de falas das entrevistadas:

C. R. Ressalta que "A música é tão rica, porque a gente consegue ter 
vários objetivos dentro dela e partindo de uma questão prazerosa de brincadeira. A gente é que sabe, a gente enquanto educador a gente sabe o que está atingindo com aquilo ali, mas a criança não, pra ela, ela está brincando, e aí eu acho que assim é um estímulo, uma questão que ele recebe muita autentico, porque ele está tão preso sabe, eu tenho que aprender aquilo, eu tenho fazer aquilo, e aí eu acredito que o aprendizado entra de uma forma muito gostosa, muito prazerosa, como deveria ser".

G. K. diz: "vejo que influencia muito a questão da oralidade, memorização, que é mais uma questão de estímulos cognitivos mesmo e principalmente a questão com dificuldade na fala, tem criança que não interage."

S. C. afirma que "a música para a educação infantil é básico, é onde a criança se comunica, onde ela explora o vocabulário, ela se expressa corporalmente, ela consegue o contato com o outro."

$\boldsymbol{K}$. L. contribui dizendo que "A musicalidade é importante para esse desenvolvimento não só da linguagem oral, mas a linguagem corporal como um todo. Ela tem tantos significados tanto didático, quanto também no Desenvolvimento Infantil, a questão dessa percepção, dessa brincadeira com a liberação, os jogos poéticos, musicais, até sonoridade mesmo a percepção sonora."

Assim, as entrevistadas concordam que a música é extremamente importante na educação infantil, pois ela trabalha as áreas psicomotoras e cognitivas, melhora a linguagem oral e o gosto musical. A criança desenvolve a percepção auditiva, a destreza, a coordenação motora, fortalece os músculos, ajuda na socialização, estimula a imaginação e a criatividade. Nessa mesma linha, Bréscia (2003) afirma:

\begin{abstract}
O trabalho de musicalização deve ser encarado sob dois aspectos: os aspectos intrínsecos à atividade musical, isto é, inerentes à vivência musical: alfabetização musical e estética e domínio cognitivo das estruturas musicais; e os aspectos extrínsecos à atividade musical, isto é, decorrentes de uma vivência musical orientada por profissionais conscientes, de maneira a favorecer a sensibilidade, a criatividade, o senso rítmico, o ouvido musical, o prazer de ouvir música, a imaginação, a memória, a concentração, a atenção, a auto-disciplina, o respeito ao próximo, o desenvolvimento psicológico, a socialização e a afetividade, além de originar a uma efetiva consciência corporal e de movimentação. (BRESCIA, 2003, p. 15).
\end{abstract}

Além disso, uma das professoras (K. T.) que leciona aulas de inglês, considera a importância da música também para reforçar os conteúdos ensinados, através da prática e da repetição, defendendo que dessa forma fica mais fácil e divertida para as crianças aprenderem a pronúncia das palavras:

K. T. "No meu caso, como professora de lingua inglesa, a gente trabalha muito a questão da repetição, e a forma sintética da língua, no caso a pronúncia, então é fundamental as músicas, todos os dias, geralmente eu faço "hello" com eles com a mesma música ou variando entre uma música e outra, pra que eles possam aprender a pronúncia das palavras." 
Já em relação à análise feita a respeito da utilização da música como forma de auxiliar o processo de desenvolvimento e aprendizagem infantil, foi possível identificar que essa pode contribuir de diversas maneiras, pois influencia na relação professor-aluno, promovendo uma maior socialização e possibilitando que a criança interaja no seu meio social e crie laços afetivos. Conforme se sabe, tal relação é extremamente importante na educação infantil, pois gera um clima de conforto e segurança, o qual garante que crianças se desenvolvam de forma mais plena e saudável.

Ressalta-se também que a música pode auxiliar nesse processo, visto que possibilita a utilização de uma metodologia diferenciada, promovendo uma aula mais lúdica e dinâmica, que estimula a curiosidade do aluno, promovendo a motivação e a criatividade, e assim as crianças aprendem sem nem perceber. Nesse sentido, as professoras têm a mesma visão.

C. R. ressalta: "De tanto eu trabalhar com música, eu percebo o comportamento diferenciado, às vezes na linguagem, às vezes no sorriso. Eu recebo crianças muito apáticas, e eu percebo, por eu gostar muito de música, que essa criança vai aos poucos tirando aquela apatia (...) Uma professora fala muito: teus meninos participam, eles falam, eles conversam. Mas eu acredito que é isso, é aquela música que eu coloco, sabe?"

G. K. diz: "Através da música a gente trabalha o desenvolvimento da criança, uma vez que esses são os referentes, então é estimulando, a música vai trabalhar a estimulação".

C. T. esclarece que "A música desenvolve em todos os fatores, porque além de trabalhar a linguagem, também contribui para o desenvolvimento corporal, [...] então além de trabalhar com eles a fonética do vocabulário eu também estou trabalhando o desenvolvimento motor quando eu peço pra eles pularem, correrem".

S. C. contribui dizendo que "A música consegue trazer essa relação entre professor, entre quem tá interagindo com ela e ele. Ela traz esse elo entre os dois. Então tem uma importância muito grande na aprendizagem sim, com certeza".

Percebe-se, assim, que todas as entrevistadas reconhecem o auxílio para a promoção do desenvolvimento e da aprendizagem. Nesse sentido, Del Ben (2002) destaca que:

A música pode contribuir para a formação global do aluno, desenvolvendo a capacidade de se expressar através de uma linguagem não-verbal e os sentimentos e emoções, a sensibilidade, o intelecto, o corpo e a personalidade [...] a música se presta para favorecer uma série de áreas da criança. Essas áreas incluem a "sensibilidade", a "motricidade", o "raciocínio", além da "transmissão e do resgate de uma série de elementos da cultura". (DEL BEN, 2002, p. 52-53). 
Por fim, no tocante a identificação das formas como a música pode ser inserida na educação infantil, verifica-se que pode acontecer de várias maneiras, não só em momentos pontuais, como em atividades de rotina ou com conteúdos curriculares, mas também trabalhando os sons da natureza, os sons que podemos fazer com o próprio corpo ou com objetos. Duas entrevistadas apontam o seguinte:

K. L. Diz que "Corporalmente falando, a gente tem aí o enriquecimento da questão da mobilidade da criança, da capacidade dela de se mover. Utilizando e fazendo o uso do ritmo ela já vai começar a marcar passos, a contar com palmas, tudo isso é musicalidade e às vezes a gente restringe a música como se fosse algo: "ah vamos escutar aqui a música do Mundo Bita, quando na verdade a sonoridade de muitas coisas, de sons podem se transformar em música [...] a gente precisa mostrar que há compassos que na verdade as crianças podem produzir sons com coisas muito pequenas eque a gente pode ampliar o leque".

C. R. contribui dizendo que "A própria natureza tem isso. A natureza tem música, tem sons, ruídos e muita coisa boa. A gente não entende porque gosta de estar dentro de uma floresta, vamos dizer assim, a gente não entende porque a gente gosta de estar diante do mar, porque é toda aquela musicalidade do mar, de um parque, de você no meio de umas árvores."

Nesse sentido, Maffioletti (2001, p.134) ressalta:

Os métodos de ensino da música mostraram que a educação musical não pode ser promovida apenas por atividades cantadas. Deslocar-se pela sala adequando-se o passo ao andamento da música; as atividades de produção e reprodução de ritmos utilizando o próprio corpo; a execução de instrumentos musicais criados pelas crianças e a criação de pequenas melodias e ritmos também devem fazer parte do planejamento. (MAFFIOLETTI, 2001, p. 134).

Nessa discussão, destaca-se ainda que a música pode ser inserida para proporcionar momentos prazerosos, nos quais o aluno pode ter instantes de terapia e relaxamento. Como ressalta a professora G. K. "É um momento de terapia, quando eu trabalho com algum fundamento, algum tipo de música, faço um momento de relaxamento, apago a luz, deixo eles ficarem bem a vontade."

Porém, o que se observa mais frequentemente é que os professores da educação infantil costumam inserir a música apenas em momentos específicos como lanche, contação de histórias, na hora da acolhida ou apenas em datas comemorativas. Como fica claro na fala de duas entrevistadas:

G. K. Diz: "Trabalho com a música nas horas de lanche, mas eu trabalho as músicas direcionadas".

S. C. ressalta que: “A música na educação é primordial em todos os 
momentos, na hora do lanche, na hora da chegada, na hora da saída, na hora que você vai fazer algum trabalho, em datas comemorativas".

A partir da análise e discussão dos dados acima, foi possível compreender a contribuição da música na educação infantil, potencializando o processo de ensino e aprendizagem dentro do espaço escolar.

Contudo, percebe-se que ainda se faz necessário ampliar os momentos em que ela aparece no contexto escolar, incluindo-a em variadas atividades e, logo, ampliando o leque de contribuição para com a educação infantil.

\section{CONSIDERAÇÕES FINAIS}

A pesquisa desenvolvida aponta que a música pode impactar positivamente no processo de desenvolvimento e aprendizagem das crianças na educação infantil, não só como mediadora da construção de conhecimentos, mas também nas dimensões corporais e socioemocionais. Para tanto, as atividades que envolvem a musicalidade dentro de sala de aula devem ser bem planejadas e executadas, buscando potencializar a capacidade lúdica que ela possui.

Destacamos que, através dos resultados apresentados, foi possível ressaltar a importância da contribuição da música no processo de desenvolvimento e aprendizagem na educação infantil, pois ela pode ser inserida como um agente facilitador em diversos aspectos, podendo ser usada não só na rotina, mas também em conteúdos e momentos de distração, trazendo leveza e fortalecendo o vínculo entre professor e aluno.

Nesse sentido, destaca-se a importância do professor na condução desse processo educativo. O ideal é que a formação desse profissional contemple conhecimentos teóricos e metodológicos que visem garantir a utilização da música da melhor maneira possível, ampliando o leque de atuação nesse espaço educativo.

Ainda que tal discussão já se faça presente há algum tempo no campo teórico, ela precisa ganhar maior notoriedade na prática cotidiana dos profissionais dentro da educação infantil.

Concluímos enfatizando que a música contribui diretamente na educação infantil e em seu desenvolvimento, auxiliando na sensibilidade, na motricidade, e no raciocínio, porém fica como sugestão que sejam realizadas pesquisas sobre esse tema, envolvendo outros participantes, outros contextos, através de outra metodologia, podendo ser realizadas pesquisas dentro de escolas que tivessem um 
olhar mais amplo, tratando do tema sob uma nova perspectiva e uma nova intervenção.

\section{REFERÊNCIAS}

ARRIBAS, Teresa Lleixá. Educação Infantil: Desenvolvimento, Currículo e Organização Escolar. 5. ed. Porto Alegre: Artmed, 2006.

BRASIL. Ministério da Educação. Lei de Diretrizes e Bases da Educação Nacional. Lei n. 9.394/96. Disponível em:

https://www.jusbrasil.com.br/busca?q=Art.\%2029\%20da\%20Lei\%209394\%2F96.

Acesso em: 20 jan. 2021.

BRASIL. Referencial Curricular Nacional para a Educação Infantil. Ministério da Educação e do Desporto. Secretaria de Educação Fundamental. V. 3. Conhecimento de Mundo.

Brasília:

$\mathrm{MEC} / \mathrm{SEF}$,

$$
1998 . \quad \text { Disponivel em: }
$$

https://issuu.com/atomoealinea/docs/educacao_musical. Acesso em: 05 fev. 2021.

BRÉSCIA, V. L. P. Educação Musical: bases psicológicas e ação preventiva. São Paulo: Átomo, 2003.

CHIARELLI. L. K. M. A música como meio de desenvolver a inteligência e a integração do ser. Instituto Catarinense de Pós-Graduação. Revista Recre@rte n. 3 Junho 2005.

DEL BEN, Luciana; HENTSCHEKE, Liane. Educação musical escolar: uma investigação a partir das concepções e ações de três professores de música. Revista da ABEM. Porto Alegre, v.13, 2002.

FARIA, Márcia Nunes. A música, fator importante na aprendizagem. Assischateau briand-Pr, 2001. 40f. Monografia (Especialização em Psicopedagogia).

GÓES, Raquel Santos. A música e suas possibilidades no desenvolvimento da criança e do aprimoramento do código lingüístico. Revista do Centro de Educação a Distância - CEAD/UDESC, Florianópolis, Vol. 2, n. ${ }^{\circ}$ 1, p. 27 - 43 mai. /jun. $2009 . \quad$ Disponível em: http://www.revistas.udesc.br/index.php/udescvirtual/article/view/1932/1504. Acesso em: 02 fev. 2021.

GILIOLI, Renato de S. P. Educação musical antes e depois de Villa-Lobos e os registros sonoros de uma época. Fundação Biblioteca Nacional. Ministério da Cultura. Programa Nacional de Apoio à Pesquisa, 2008.

GODOI, Luiz Rodrigo. A importância da música na educação infantil. Londrina PR. Tese apresentada a Universidade Estadual de Londrina, 2011.

MAFFIOLETTI, Leda de Albuquerque. Práticas musicais na Escola Infantil. Educação Infantil. Pra que te quero? Porto Alegre, v.1, n.1, p.123-134, 2001. 
MARCONI, M. de A.; LAKATOS, E. M. Técnicas de pesquisa. 6. ed. rev. ampl. São Paulo: Atlas, 2007.

MORENO, Gilmara Lupion. Organização do Trabalho Pedagógico na Instituição de Educação Infantil. In: PASCHOAL, Jaqueline Delgado (Org.). Trabalho Pedagógico na Educação Infantil. Londrina: Humanidades, 2007, p. 54-62.

NOGUEIRA, C. M .I. Tendências em Educação Matemática escolar: das relações. Aluno-professor e o saber matemático. In: ANDRADE, D.; NOGUEIRA, C. M. I. org. Educação Matemática e as operações fundamentais. Maringá: EDUEM, 2005.

NOGUEIRA, M. A. A música e o desenvolvimento da criança. Revista da UFG, v. 5, n.2, 2003.

OLIVEIRA, Gislaine de Campos. Psicomotricidade: educação e reeducação no enfoque psicopedagógico. 9. ed. Petrópolis: Vozes, 1997.

RIBEIRO, Antonio de Lima. Gestão de Pessoas. São Paulo: Saraiva, 2006.

UNESCO. Banco Mundial. A criança descobrindo, interpretando e agindo sobre o mundo. Brasília: Fundação Maurício Sirotsky Sobrinho, 2005.

\section{APÊNDICE A - Entrevista semiestruturada com as professoras}

1) Para você, qual a importância da música na Educação Infantil?

2) Você acredita que a música pode contribuir no processo de desenvolvimento e aprendizagem da criança? /De que maneira?

3) A música costuma fazer parte do seu cotidiano escolar dentro da educação infantil? De que forma? Em quais momentos?

4) Você observa benefícios do uso da música no dia a dia da sala de aula? Quais?

5) Você identifica alguma dificuldade para utilização da música no contexto escolar? Quais?

6) Na sua opinião, a música é valorizada no contexto escolar?

7) A música pode ser multidisciplinar? 